\title{
ESTUDO NUMÉRICO E EXPERIMENTAL SOBRE A APLICAÇÃO DO CICLO OTTO - ATKINSON EM UM MOTOR PFI
}

\author{
Thomaz Ernesto de Sousa Savio ${ }^{1.2}$, Ézio Castejon Garcia ${ }^{1}$ e Marcos Fregoneze ${ }^{2}$ \\ ${ }^{1}$ ITA - Instituto Tecnológico de Aeronáutica \\ ${ }^{2}$ Ford Motor Company \\ E-mails: tsavio@ford.com, tsavio47@gmail.com, ezio@ita.br,mfregone@ford.com
}

\section{RESUMO}

O propósito deste trabalho é simular, implementar e analisar os efeitos do ciclo teórico de Otto-Atkinson em um motor comercial de veículos leves usando controle de carga através da variação do ponto de abertura das válvulas de admissão e escape.O ciclo teórico de OttoAtkinson consiste em reduzir o curso de compressão quando o motor opera em carga parcial, seja mantendo as válvulas de admissão abertas durante o início do curso de compressão ou fechando-as antes do final do curso de admissão, refletindo assim em maior eficiência térmica. Neste trabalho foi utilizado um motor Ford Sigma 1.6L TiVCT de 4 cursos, 4 cilindros, ignição por centelha, naturalmente aspirado e de injeção de combustível na porta (PFI), sendo ensaiado em dinamômetro na configuração original e protótipo, sendo este último contendo pistões, bielas e eixos de came modificados. As configurações de melhor ponto de válvulas no regime de Otto-Atkinson foram obtidas usando simulações de performance, a partir de tal o motor for reprojetado para conseguir operar nas condições desejadas. Além das simulações de performance, foram realizadas simulações de rodagem do veículo[1], sendo possível calcular o reflexo da implementação do sistema na média de consumo do veículo.

\section{INTRODUÇÃO}

A busca por novas tecnologias que aumentem a eficiência energética dos motores de combustão interna está cada vez mais presente na indústria automotiva, as novas regulamentações de consumo de combustível e emissão de poluentes obrigam as montadoras a inovar, não só no motor, mas no veículo como um todo, em busca da excelência para se manter competitiva no mercado.

O ciclo teórico de Otto Atkinson exige versatilidade do motor, o que implica no uso de alta tecnologia construtiva para operar nas condições limítrofes do ciclo. Por muito tempo os estudos referentes ao ciclo de Otto Atkinson não foram possíveis pela ausência da tecnologia construtiva necessária a operação do motor.

\section{MATERIAIS E MÉTODOS}

O uso de ferramentas computacionais acarreta em desenvolvimentos mais rápidos e com menor custo, o que reflete em vantagens competitivas. Para a simulação de motores a combustão interna existem diversas ferramentas no mercado, neste trabalho foi utilizado o software DIESEL-RK [5]. 
A estratégia de simulação deste trabalho começou com a construção do modelo do motor baseado em uma ampla base da dados dinamométricos, estando o modelo adequadamente maduro, ou seja, conseguindo replicar em simulações os resultados obtidos em dinamômetro em toda a faixa de rotação e carga do motor com divergência inferior a $5 \%$, partiu-se para as simulações do ciclo de Otto-Atkinson, buscando através de varreduras as melhores configurações de aplicação.

Foram calibrados os modelos de trocas térmicas, fluxo mássico de ar, combustão [2], aberturas de válvulas e atrito, foram considerados parâmetros de controle o ponto de centelha, o ponto de abertura da válvula de admissão, o ponto de abertura da válvula de escape, a relação de equivalência, a pressão no coletor de admissão e a rotação do motor. Os parâmetros quem mensuraram a correlação foram pressão média efetiva de atrito, fluxo de calor no sistema de arrefecimento, fluxo mássico de ar na admissão, ângulo de fração queimada, torque, potência e consumo específico de combustível.

A estratégia de busca da melhor configuração de válvulas foi realizada através de varreduras, a faixa de rotação do motor foi dividida em breakpoints, e em cada rotação analisada foi feita uma varredura de 36 diferentes configurações de pontos de válvulas considerando a pressão plena no coletor, ou seja, borboleta totalmente aberta. A figura 1 mostra a nuvem de pontos gerada pela varredura de configurações de comando em uma rotação específica.

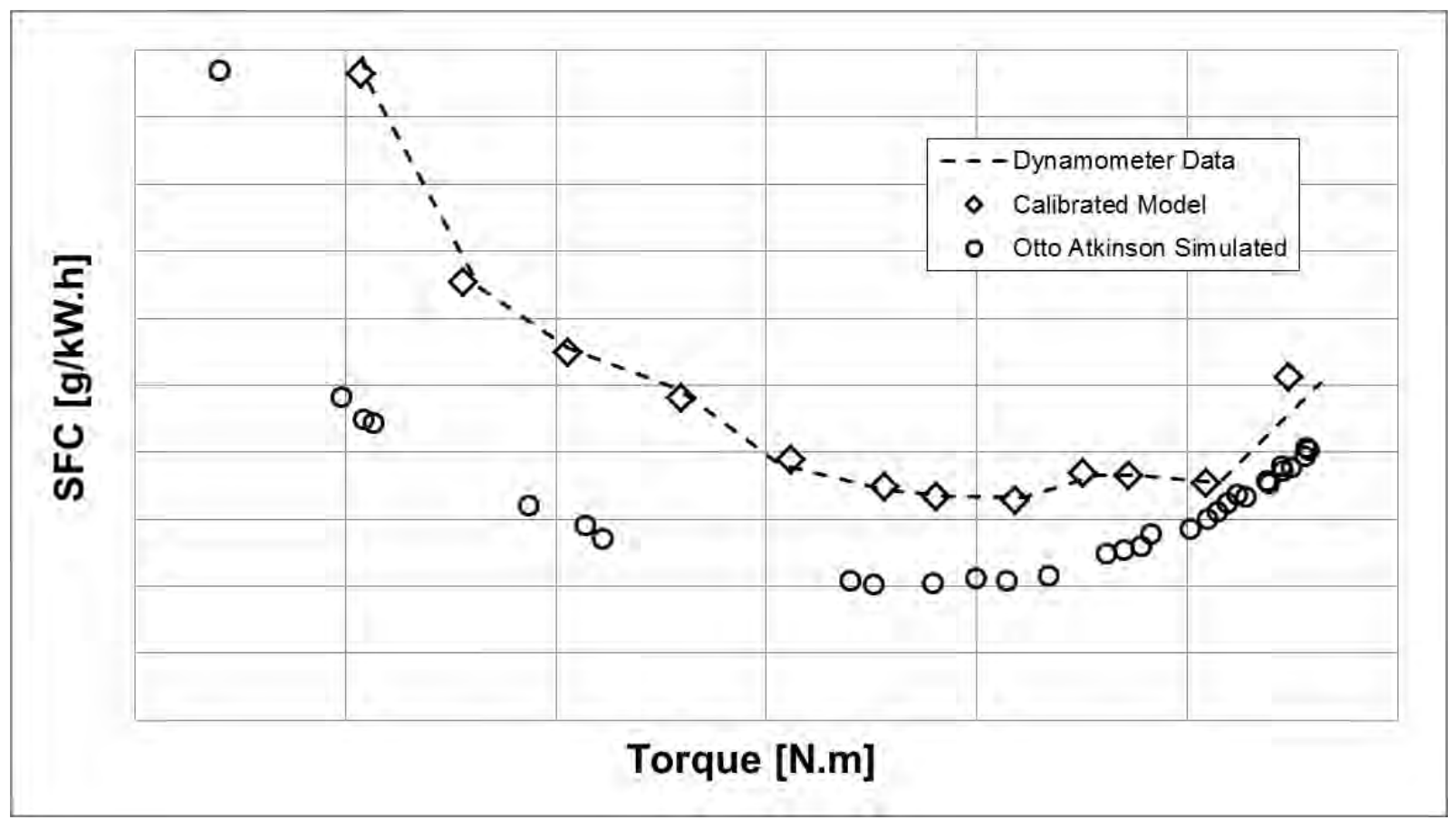

Figura 1: Nuvem de pontos da varredura de configurações de válvulas para uma rotação específica.

Um conjunto de pontos da nuvem vão formar a série que resulta na operação mais eficiente do motor ao longo da carga, chamado então de "família ótima". Os resultados de performance dos pontos pertencentes a família ótima vão alimentar o software de simulação de rodagem, que irá predizer o consumo de combustível do motor [2] operando nestas configurações. Fazendo a mesma análise com os dados do motor original, conseguimos predizer o ganho efetivo de economia de combustível. 
Uma vez comprovada a maturidade do sistema de simulação e conhecidas as famílias ótimas que geram resultados favoráveis do ciclo de Otto-Atkinson, é possível projetar as modificações desejadas no motor. Neste trabalho foram modificados os pistões, os eixos de cames, as bielas e algumas configurações de montagem, de modo que é possível fazer com que a janela de operação do sistema de comando de válvulas variável atue na região que se encontram as famílias ótimas.

Montado o motor protótipo foi possível repetir em dinamômetro a varredura de configurações de válvulas. Poderia-se optar por testar apenas as configurações das familias ótimas, porém a varredura foi refeita em dinamômetro para analisar a fidelidade do modelo de performance quando operando fora da faixa de variação do comando de válvulas variável calibrada e assim garantir ou revisar as configurações de família ótima. Confirmadas ou redefinidas as famílias ótimas, os resultados alimentaram o software de simulação de rodagem onde pode-se calcular o ganho de eficiência real da aplicação.

Foi tomado o cuidado de ensaiar o motor protótipo e o motor de correlação no mesmo dinamômetro, usando os mesmos periféricos do motor e com o mesmo grau de amaciamento seguindos as instruções de [3] e [4]. Na data de realização dos testes só existia disponível no mercado o combustível gasohol nivel E27 enquanto que os dados de calibração do modelo foram ensaiados com gasohol nivel E22 (combustível corrente no mercado quando se iniciaram os estudos), portanto é esperado uma diferença nos resultados de SFC entre simulação e dados dinamométricos dado que o poder calorífico inferior do E27 é menor que do E22, por outro lado, é esperado o mesmo comportamento da nuvem de pontos frente a varredura de configurações de comandos de válvulas.

\section{RESULTADOS E DISCUSSÃO}

As simulações de performance mostraram que a aplicação do sistema de Otto Atkinson no motor em estudo resultaria em ganho de eficiência, ainda na figura 1 pode-se constatar que toda a nuvem de pontos Otto-Atkinson consegue, em toda a faixa de carga, entregar o mesmo torque com menor SFC. O mesmo pode ser concluído nas outras rotações analisadas.

As famílias ótimas obtidas experimentalmente foram muito semelhantes as famílias ótimas obtidas por simulações, a figura 2 mostra os resultados de varredura agrupados por pontos com o mesmo ângulo de abertura de válvula de admissão. 


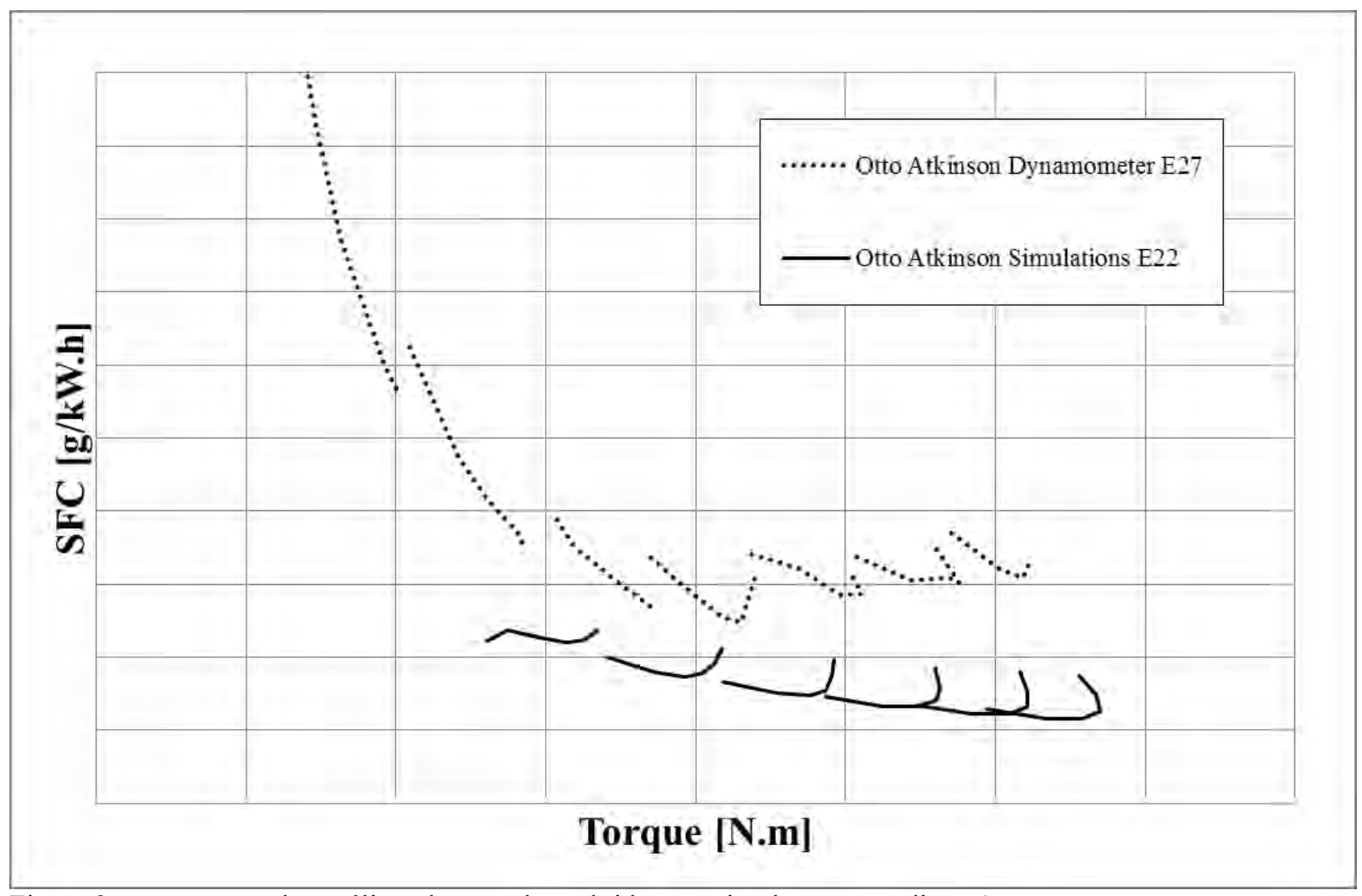

Figura 2: comparação das análises de varredura obtidas por simulação e em dinamômetro.

A influência do poder calorifico do combustivel fica evidente na figura 2, o formato da nuvem de pontos quando separada por grupos de mesmo angulo de abertura de válvula de admissão revela o mesmo perfil de comportamento ao longo da carga.

A figura 2 também mostra os efeitos negativos de baixa carga encontrados em dinamômetro. As configurações de válvulas que atingem cargas baixas implicam em maior fração residual de gases e maior fluxo indesejado de combustível para o sistema de exaustão, o que piora a performance e a estabilidade do motor, porém mesmo com esta piora o consumo específico de combustível do motor em carga baixa ainda é vantajoso frente ao encontrado no motor original.

Nas rotações mais altas, as faixas de operação do comando de válvula variável não contemplavam mais os configurações de máxima potência, sendo assim foi observado uma queda de potência máxima na ordem de $14 \%$. É preciso ressaltar que este efeito é totalmente neutralizado se utilizarmos um sistema de comando de válvulas variável com amplitude de atuação maior. A figura 3 demonstra a redução de torque máximo observado em alta rotação. 


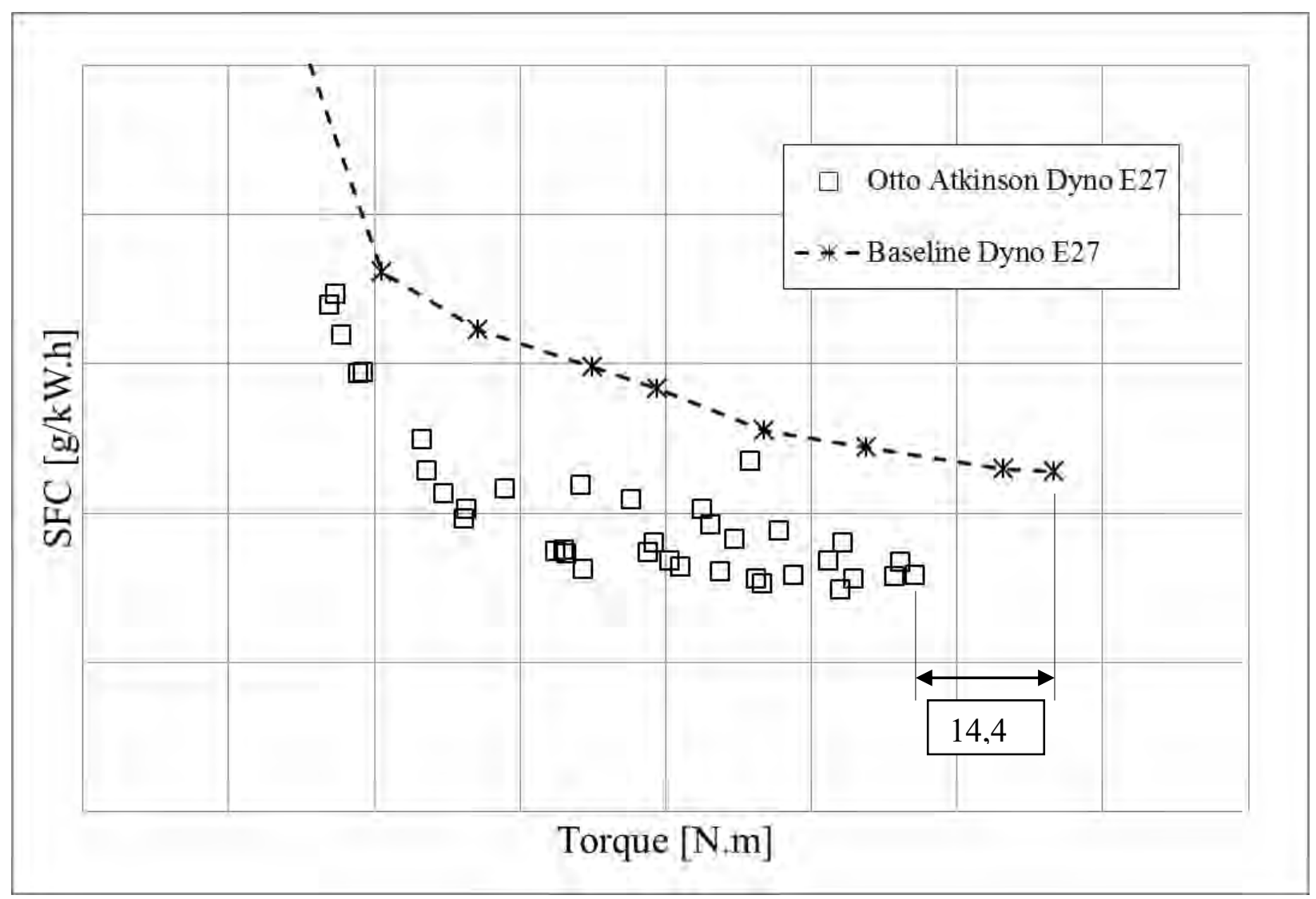

Figura 3: Queda de performance em rotação de potência máxima.

A análise de performance das famílias ótimas obtidas em dinamômetro comparadas as curvas de performance do motor de correlação, usando o software de simulação de performance baseado no ciclo de condução EPA [5] resultaram em melhoria de $5.87 \%$ no consumo de combustível do veículo, como mostra a tabela 1.

Tabela 1: Melhoria de economia de combustível.

\begin{tabular}{|c|c|}
\hline Ciclo de condução & Melhoria de economia de combustível \\
\hline EPA City & $8.70 \%$ \\
\hline EPA Highway & $3.99 \%$ \\
\hline EPA Combinated & $5.87 \%$ \\
\hline
\end{tabular}

\section{CONCLUSÃO}

Neste trabalho, embasado em simulações computacionais e testes dinamométricos, foi possível confirmar que a aplicação do ciclo teórico de Otto-Atkinson em um motor de injeção na porta resulta em redução de consumo de combustível na ordem de 5.8\%.

Se usado um motor com amplitude do sistema de variação de válvulas maior a queda de potência observada poderia ser anulada. Usando um motor de injeção direta de combustível os efeitos prejudiciais de baixa carga também seriam anulados e assim os resultados finais seriam ainda mais expressivos. 


\section{REFERÊNCIAS}

[1] Savio. Et. Al. 2014, Simulation of Vehicle Performances Based on Characteristics Curves of Engines, ENCIT, Belém, Brazil.

[2] Savio. Et. Al. 2014, Experimental Study About E22 Combustion in Ford Sigma 1.6l TiVCT Engine, ENCIT, Belém, Brazil.

[3] NBR ISO 1585 - Road Vehicles - Engine test code - Net power, ABNT, Rio de Janeiro RJ, 1992.

[4] A. J. Martyr, M. A. Plint, 2007, Engine Testing Theory and Practice, Elsevier, Burlington, $3^{\text {rd }}$ edition. ISBN 978-0-7506-8439-2

[5] Kuleshov, Andrey. Diesel RK website. Available in http://www.diesel-rk.bmstu.ru/Eng/ Accessado em: 12/05/2014.

[6] Brunetti, F., 2012, Motores de Combustão Interna, Blucher, São Paulo, $1^{\text {st }}$ edition.

[7] Taylor, C. F., 1985, The Internal Combustion Engine in Theory and Practice, MIT press, Cambridge, $2^{\text {nd }}$ edition. 